\title{
A Novel Method to Identify the Global Sources and Sinks of Carbon Dioxide Based on Spatial Analysis
}

\author{
Ali Madad1 ${ }^{*}$, Babak Naimi', Saeidi Anjileh Mehdi² \\ ${ }^{1}$ Department of Environment and Energy, Faculty of Science and Research Branch of Islamic Azad University, \\ Tehran, Iran \\ ${ }^{2}$ Department of GIS/SDI, National Cartography Center of Iran, Tehran, Iran \\ Email: ${ }^{*}$ alimadadmsbk@yahoo.com
}

Received 12 March 2015; accepted 3 April 2015; published 7 April 2015

Copyright (C) 2015 by authors and Scientific Research Publishing Inc.

This work is licensed under the Creative Commons Attribution International License (CC BY). http://creativecommons.org/licenses/by/4.0/

(c) (i) Open Access

\section{Abstract}

Today global warming has become one of the most important concerns of environmental science. The redundancy of greenhouse gases in the atmosphere is known as a major factor in this phenomenon. These gases contain water vapor, carbon dioxide, methane, nitrous oxide, and ozone. The $\mathrm{CO}_{2}$ gas is one of their most effective among these gases. According to scientific warnings, the amount of $\mathrm{CO}_{2}$ gases in the atmosphere has increased by $40 \%$ to $45 \%$ over the last 50 years. Reducing the abundant gas in the atmosphere requires a good knowledge of related factors involved, including sources that emit gases into the atmosphere and sinks that absorb the gas from the atmosphere. The amount of $\mathrm{CO}_{2}$ gas in the atmosphere has been accurately measured in previous years with great certainty. But the predicted values of emissions from sources and removals by sinks have large ambiguities. As studies show, even the computed residuals trends (which is obtained by subtracting the amounts of sinks from sources) strongly disagree with the trends of the existence of $\mathrm{CO}_{2}$ in the atmosphere. This study as a preliminary review, proposes a method to identify the locations of sources and sinks of carbon dioxide using global statistical information and adding spatial analysis approaches. By applying this method to the data observed from 2000 to 2011 and the extraction of likely sources and sinks, the region of the Black Sea, near Romania recognized as one of the strong points issued and Bukit Kototabang near Indonesia acknowledged as an Impressive $\mathrm{CO}_{2}$ absorption zone.

\section{Keywords}

Carbon Dioxide Sink, Spatial Autocorrelation, Interpolation, Volcanic Shape

\footnotetext{
${ }^{*}$ Corresponding author.
} 


\section{Introduction}

Orientation of global warming and its effects, especially in the Arctic, is quite obvious, and the main reason for this is the redundancy of $\mathrm{CO}_{2}$ in the atmosphere [1]. To study the association between elevated atmospheric $\mathrm{CO}_{2}$ and global warming, several studies have been conducted with different methods. Most of the approaches are the analysis of temperature data as well as the increase of atmospheric $\mathrm{CO}_{2}$ extraction process. Due to the growing trend of global temperature and the rapid increase in atmospheric $\mathrm{CO}_{2}$, the impression that there is a link between them is reinforced [2]. Assuming the establishment of such a link, Salahi et al. (2006) by simulating changes in temperature and precipitation in Tabriz city in terms of doubling of atmospheric carbon dioxide conclude that in this case, the temperature for all seasons increase significantly [3]. Carbon dioxide measurements in the atmosphere are very precise and show the annual growth of the accumulation in the atmosphere of the earth. Despite this certainty, the amount of carbon dioxide produced by the earth cannot be determined yet. Also the amount of gas absorbed by the land and oceans is not determined [4], although a substantial sum is formed. For example, the most important way of reducing carbon dioxide in the atmosphere after reducing the consumption of fossil fuels is carbon storage in terrestrial ecosystems and land. Soil contains $75 \%$ of the land carbon source [5]. Determining the emission or absorption of carbon dioxide in the atmosphere requires a detailed knowledge of at least one of them. By subtracting the amount of gas in atmosphere we can obtain the other. Reaching this trust requires a wide range of global geophysical and economic data. Corinne Le Quéré (2009) prepared an overall rate of all production and absorption of carbon dioxide from 1959 to 2008 to develop and analyze the phenomena that affect them. The growth rate of carbon dioxide in the atmosphere was determined on the basis of direct measurements. The amount of carbon dioxide produced by fossil fuels was detected according to statistics from the consumption of fossil fuels in different countries. The amount of carbon dioxide that comes from land use changes was estimated by statistical deforestation, land use, spatial observations fires, and assumptions about the carbon density in the vegetation and soil. The result of the operation shows that the amounts of the estimated residuals were not compatible with the quantity of gas in the atmosphere. The inability to identify the source and extent of absorption and excretion of carbon dioxide prevents accurate understanding of the carbon cycle [4]. The purpose of this article is to present a method to identify locations where gas adsorption or desorption may have occurred. This method works by implementing spatial analysis in the global statistical information quantities of gas in the atmosphere.

\section{Source and Sink Trends}

Most studies on the precise knowledge of the factors that influence the uptake and release of carbon dioxide began around the 1990s. These studies can be divided into two groups: 1) Assessment of changes in carbon dioxide in the atmosphere, and understanding the effective factors that cause them. 2) Statistical analysis of climate data and maps to predict the spread and absorption of gases. If the amount of carbon dioxide in the atmosphere is the balancing result of known sources and sinks, according to the known factors that influence the absorption and release of carbon dioxide gas the budget can be shown as indicated by the following equation [6]:

$$
\text { Fossil }+ \text { Land Use }+ \text { Ocean }+ \text { Terrestrial Biota }=\text { Trend }
$$

The trend of carbon dioxide in the atmosphere is equivalent to the sum of the amount of gas emitted by the sources and absorbed by the sinks. According to measuring stations on the surface of the Earth, an average of $40 \%$ of the total annual $\mathrm{CO}_{2}$ emissions between 1959 and 2008, remain in the atmosphere. But this number, as shown in Figure 1 [4] [7], has also high annual variations too.

The amount of $\mathrm{CO}_{2}$ emission values with the absorbed $\mathrm{CO}_{2}$ is called residual values. The trend chart is shown in Figure 2 [4] [8]. The range in which the shadow appears, the calculation is approximate.

As the comparison between Figure 1 and Figure 2 shows, the trend of changes in atmospheric carbon dioxide does not justify the fluctuations of its calculated residual amounts. In other words, the growth rate of $\mathrm{CO}_{2}$ in the atmosphere does not correspond with the calculated emissions and absorptions [4].

Geostatistical analysis is another way that is used to learn more about the carbon cycle. Using two methods of neural networks and fuzzy network on meteorological data in Tehran, Khazaei et al. (1391) predicted the concentration of carbon monoxide emissions. 


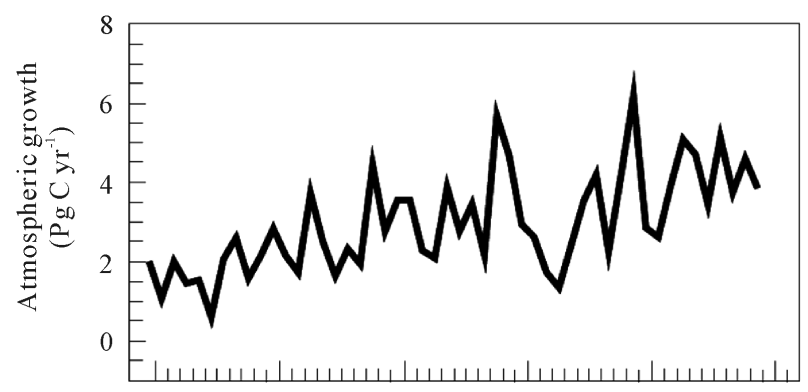

Figure 1. The annual fluctuations of $\mathrm{CO}_{2}$ emissions in the atmosphere [4] [7].

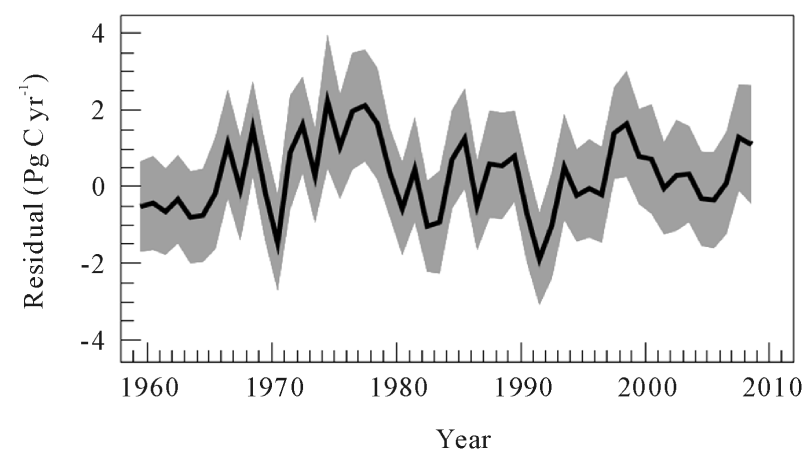

Figure 2. Residual annual fluctuations in atmospheric $\mathrm{CO}_{2}$ [4] [8].

\section{Material and Methods}

All arithmetic operations used in the studies mentioned in the previous section, are often limited to the statistical analysis of (non-spatial) descriptive data, while the spatial resolution with its good analytical equipment that is able to identify areas with certain characteristics in the environment is suitable to apply. The importance of the method presented in this study is its approach in using this kind of analysis.

The data used in this study were carbon dioxide values in the atmosphere between 2000 and 2011 that is measured by 63 sampling stations, through the database offered in GLOBAL VIEW. Information available on this site starts from 1999. Prior to 1988, the number of measurement stations was much less. Studies show that at least 10 stations for each study area are required to obtain good estimates [9]. The samples are offered both daily and monthly. By calculating the average of monthly data, annual values for each station were calculated and used. Using the geographical coordinates of stations and a view of world map, the working platform was prepared. Using polygon analysis of Thiessen, the functional areas of each station is shown in Figure 3.

Using annual data for each station and their geographical positions, a Triangular Irregular Network (TIN) model was produced. Figure 4 illustrates an example of this model for 2009.

Then by using the TIN models, the contour maps were generated from them. By implementing a method that will be explained in the next section, for each station a numerical value proportional to its role in the sink or source of the region obtained. These values are named in this paper by "Stations Volcanic Degree" (SVD). In conclusion, the amounts of these SVDs were compared during 2000-2011.

\subsection{Stations Volcanic Degree (SVD)}

The objective is that with the help of obtained models, the areas where they can absorb or emit gases are identified. TIN models are something like the earth terrain. It is possible to see some lumps and troughs over them. Height of the hills or mountains illustrates the high amount of value in that area. And depth of the valleys shows the low amount of the value over there.

In the nature, the volcanic mountains with their simple conical shapes were created by the magma at their beneath. This means that the factors which create them are at their below and not any other further places. This 


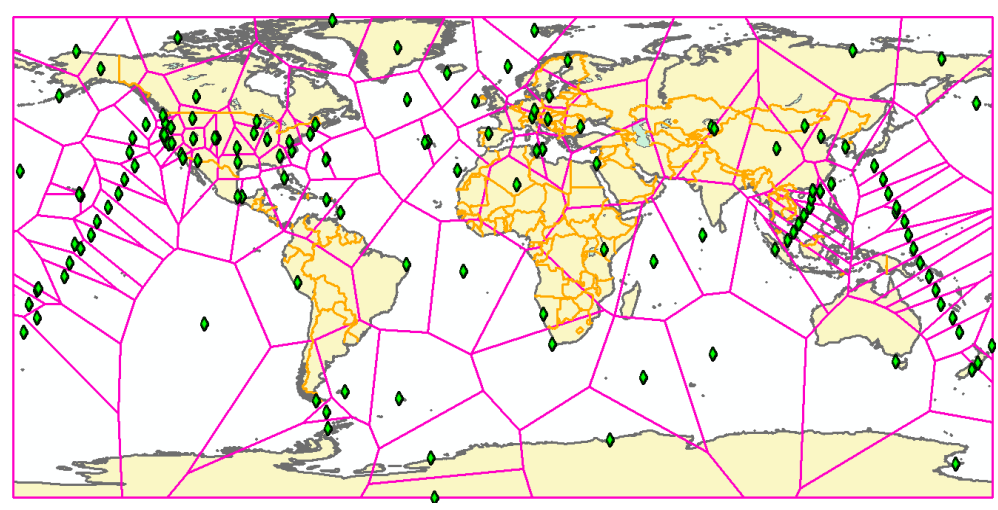

Figure 3. Functional areas of measuring stations.

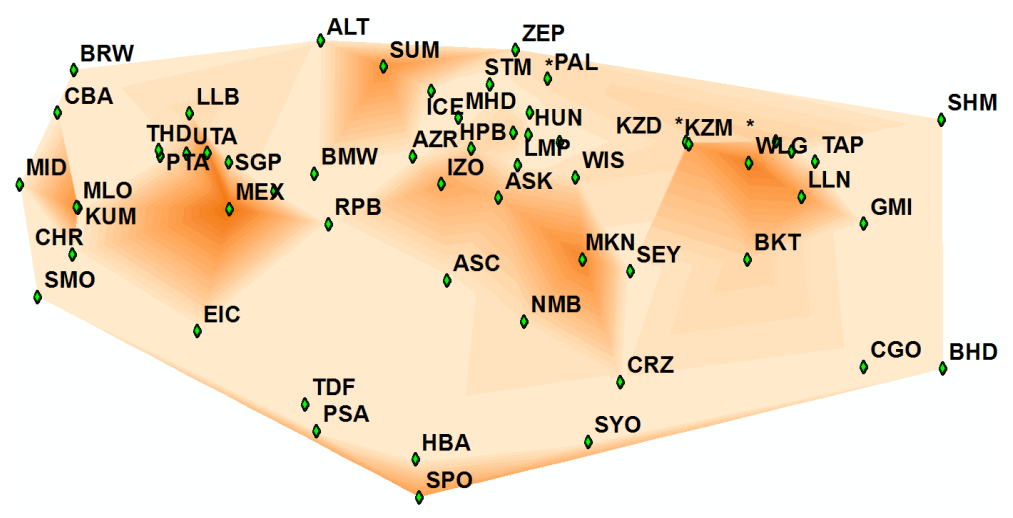

Figure 4. TIN model for values of $\mathrm{CO}_{2}$ in 2009.

feature leads to the concept of detecting volcanic forms in the TIN models to find the places where the emission or absorption was occurred. The volcanic mountains have their own characteristic shapes. In Figure 5, the three main types of volcanic formation are reported [10]. In this view, the formations of peaks are more important than their heights. For example, the elevated Himalayan peaks over 8000 meters are considered much more non-volcanic mountains than a single volcanic mount such as Ararat or Damavand with their less than 6000 meters height.

Because of the symmetry, the same calculation for the identification and classification of volcanic peaks was used to identify canyons in the reverse mode (gas resources or reductions).

Similar to the individual characteristics of volcanic peaks, with the method shown in Figure 6, and using contour maps, the characteristics of peaks and valleys were extracted and initialized their SVDs values based on the amounts of volumes enclosed by them. It is assumed that the absolute value of SVD indicates the possibility of locating the gas creative factor in the position of the station.

\subsection{Model Validities}

This research was conducted in two types of validations: 1) The existence of a spatial relationship between the numerical values of measurement stations. 2) Evaluation of Triangular Irregular Network model (TIN). The following sections explain how to perform each of these surveys.

\subsubsection{Validating Spatial Relationship}

After preparing the data it is necessary to assess whether the reported gas values of stations have a spatial relationship. For this purpose, the spatial autocorrelation analysis was used. Spatial autocorrelation suggests that the things which are closer to each other are much more similar than the far ones. If this feature is not seen in the numerical values, then the spatial relationship between the numbers do not exist, and thus the use of spatial analysis in them will not be correct. To view this autocorrelation, the Variogram Cloud chart is used. The pairs 


\begin{tabular}{|c|c|}
\hline Volcano Type & Volcano Shape \\
\hline Cinder Cone & Steep conical hill with straight sides \\
\hline Shield Volcano & $\begin{array}{c}\text { Very gentle slopes; convex upward } \\
\text { (shaped like a warrior's shield) }\end{array}$ \\
\hline Stratovolcano & $\begin{array}{c}\text { Gentle lower slopes, but steep upper } \\
\text { slopes; concave upward }\end{array}$ \\
\hline
\end{tabular}

\section{Figure 5. Three main types of volcanoes [7].}

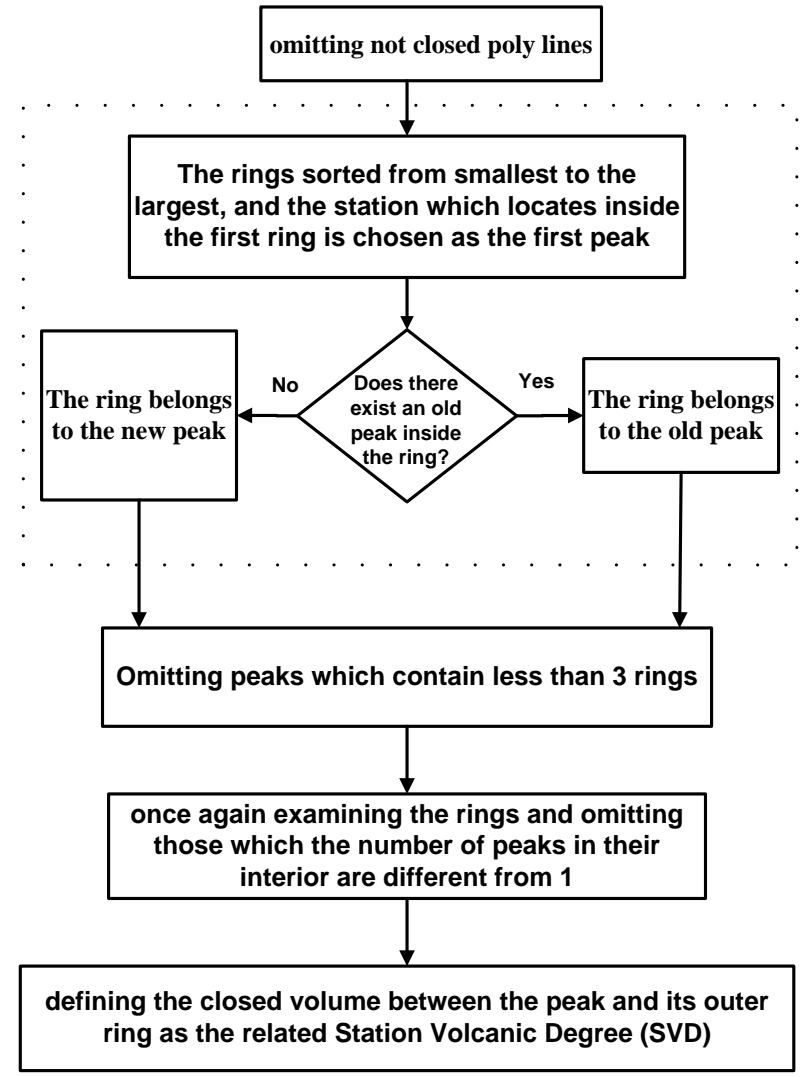

Figure 6. The SVDs rankings for assessing stations.

of points which are close to each other have the similar values. In contrast, the pairs that are far from each other are less similar set (Torabi 1389). The survey results will be generalized to the cases of similarity and dissimilarity. The Moran index is used to assess the similarities and the Geary method is used for dissimilarity. In Moran, the results of the calculations would be a number between 1 and -1 . Number 1 indicates a perfect positive similarity and -1 indicates a perfect negative similarity. In this study, the Geary method was used to evaluate the dissimilarity. In Geary method, on the basis of function (2), by comparing a pair, a number between 0 and 2 will be obtained. Values less than 1 indicate a positive correlation and values above 1 Show negative autocorrelation. The value 1 displays the absence of autocorrelation. 


$$
I=\frac{(N-1)}{2 \sum_{i} \sum_{j} W_{i j}} \times \frac{\sum_{i} \sum_{j} W_{i j}\left(X_{i}-X_{j}\right)^{2}}{\sum_{i}\left(X_{i}-\bar{X}\right)^{2}}
$$

The variable $N$ is the number of samples. The variables $X_{i}, X_{j}$ are the values of two samples pending. Variable $W$ determines whether two samples are within the specified distance. The function (3) can be used to determine the level and type of spatial relationship between values.

$$
2 \gamma(d)=1 / n_{d} \sum_{i} \sum_{j} w_{i j}\left(X_{i}-X_{j}\right)^{2}
$$

$n$ is the number of samples in the specified interval. Consequently, the calculation leads to a graph which shows the amount and type of the spatial relationship between the values. Figure 7 shows the result of this operation for the values of stations in 2009.

The charts show the existence of spatial relationship of exponential type, between the values of stations in 2009. Therefore, the spatial analysis on the data is acceptable

\subsubsection{Validating TIN Model}

TIN models are generated by interpolation processes. For validating the interpolation method, $15 \%$ of the stations was kept and with the rest of them a three dimensional surface was generated by TIN Model. Then the predicted values of TIN model for the locations of the excluded stations were compared to their actual values. The test was performed 20 times with the 2009 data. Average relative error of $0.7 \%$ was achieved in the experiments. So, the use of the TIN model for the spatial analysis of stations values is acceptable. Figure 8 shows the relative errors that have been drawn in ascending order.

As it is shown, the main results of errors are around zero. There are some cases that have much difference. These cases may be a sign of the gas emission or absorption in their areas.

\section{Results}

Figure 9 shows an example of the results of this paper in relation to 2009 data.

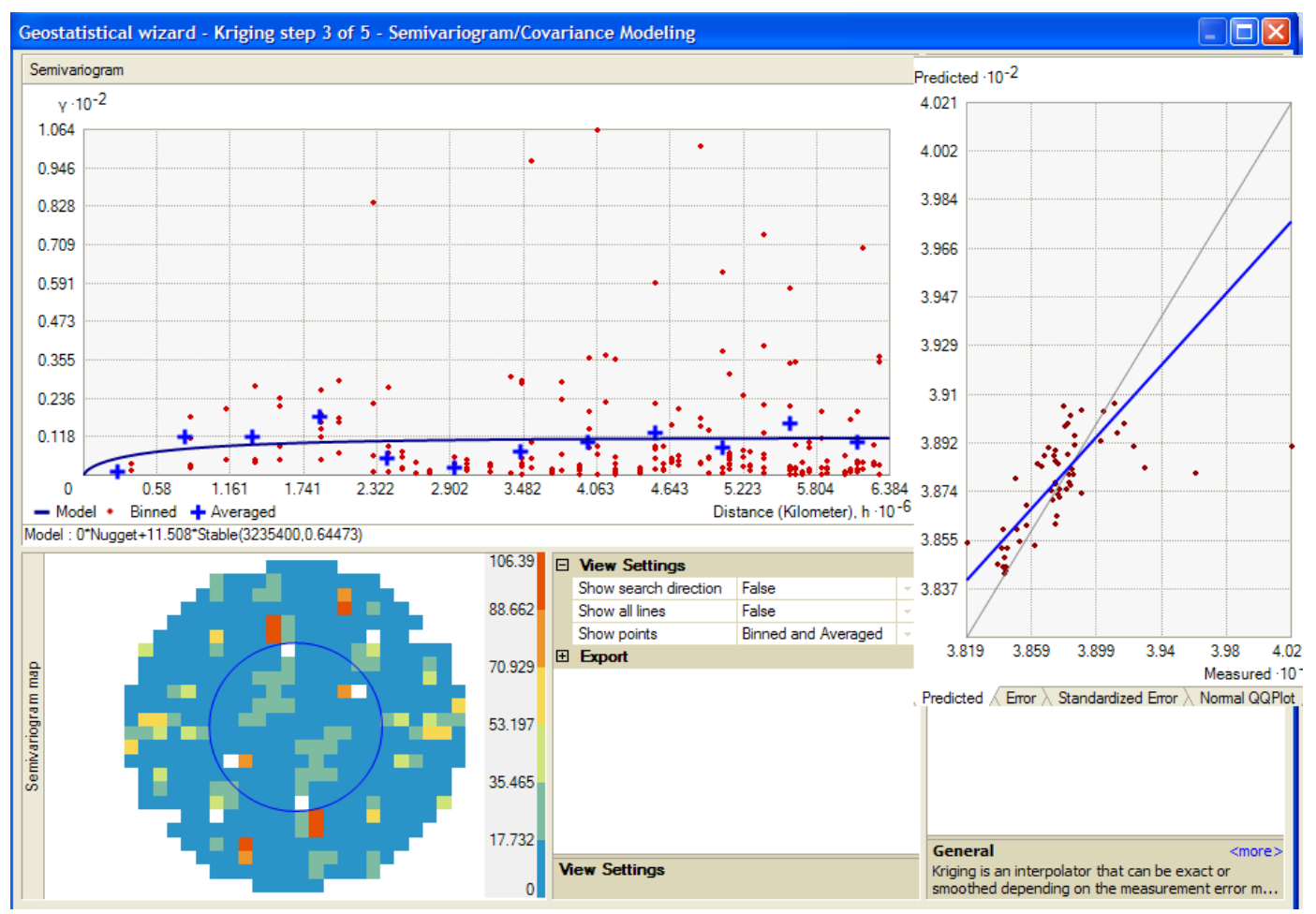

Figure 7. Spatial relationship diagrams for numeric values of 2009. 


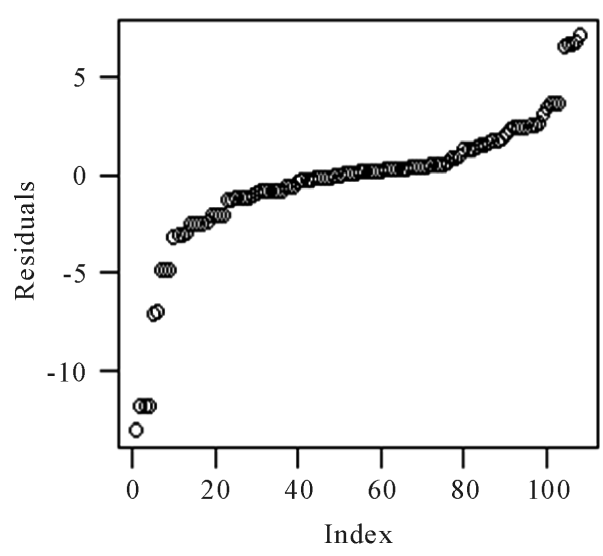

Figure 8. Variations between observed and predicted values.

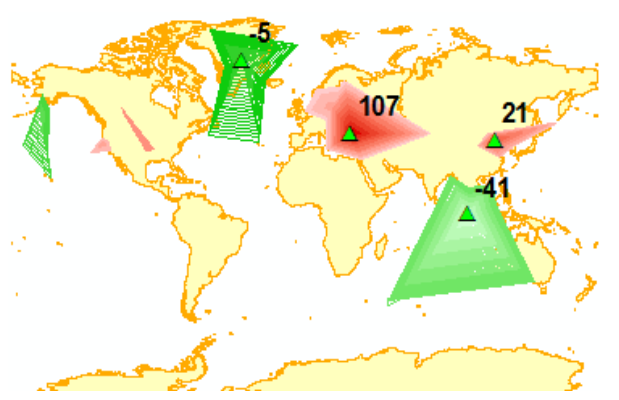

Figure 9. The greatest SVDs for 2009 data. Most top sinks (greens) and sources (reds).

In this case, the strongest peak, with 107 SVD value is known at the BSC station in the "Black Sea" area. The strongest valley with SVD value of -41 is known at the BKT position near "Indonesia". With these assumptions, the probability that in 2009 at the Black Sea region a strong $\mathrm{CO}_{2}$ emission factor being founded is much more than any other place. In addition, the gas absorption factor in the position of Indonesia station will be more discoverable. By applying the proposed method, to $\mathrm{CO}_{2}$ values of stations during 2000 to 2011, the 12 maps were produced. In each map the peaks and valleys were illustrated. The peaks and valleys were graded with their SVD values. Table 1 shows 10 stations that have the highest degree of positive and negative values of SVD.

Table 1 show that there is a strong domination in the BSC and BKT stations from all others. The station of the Black Sea (BSC), with its high SVD values, shows the highest degree of $\mathrm{CO}_{2}$ emission zone, and can be a good option for discovering the $\mathrm{CO}_{2}$ emission factors. This inference exists while the average values measured at the station is something close to the average of the others, and apparently no particular dominance over others, can be seen. And the Indonesia station (BKT) is recommended as a priority area for detecting $\mathrm{CO}_{2}$ gas absorption factors. The SVD value of the PAL station has always been negative, and only in 2001 became largely positive. It can also be a sign of a temporary source of $\mathrm{CO}_{2}$ emissions in 2001 in the region. Figure 10 shows the location of these stations.

\section{Conclusion}

In this paper, using the measuring stations annual data of carbon dioxide in the atmosphere and their locations, a TIN model was produced for each year. Then with a model that has been proposed based on the idea of the formation of volcanic mountains, the peaks and valleys of the TIN model were rated based on their similarities with forms of volcanic mountains. These grades were saved as Station Volcanic Degree (SVD). It is assumed that the special formation of volcanoes could be a suitable pattern for extracting those peaks and valleys of the TIN model which the related sources or sinks are located inside their own regions. By considering the computation results on data from 2000 to 2011, possible source locations of gas emission and adsorption were offered. As 
Table 1. 10 stations that have the highest degree of positive and negative values of SVD between 2000 to 2011.

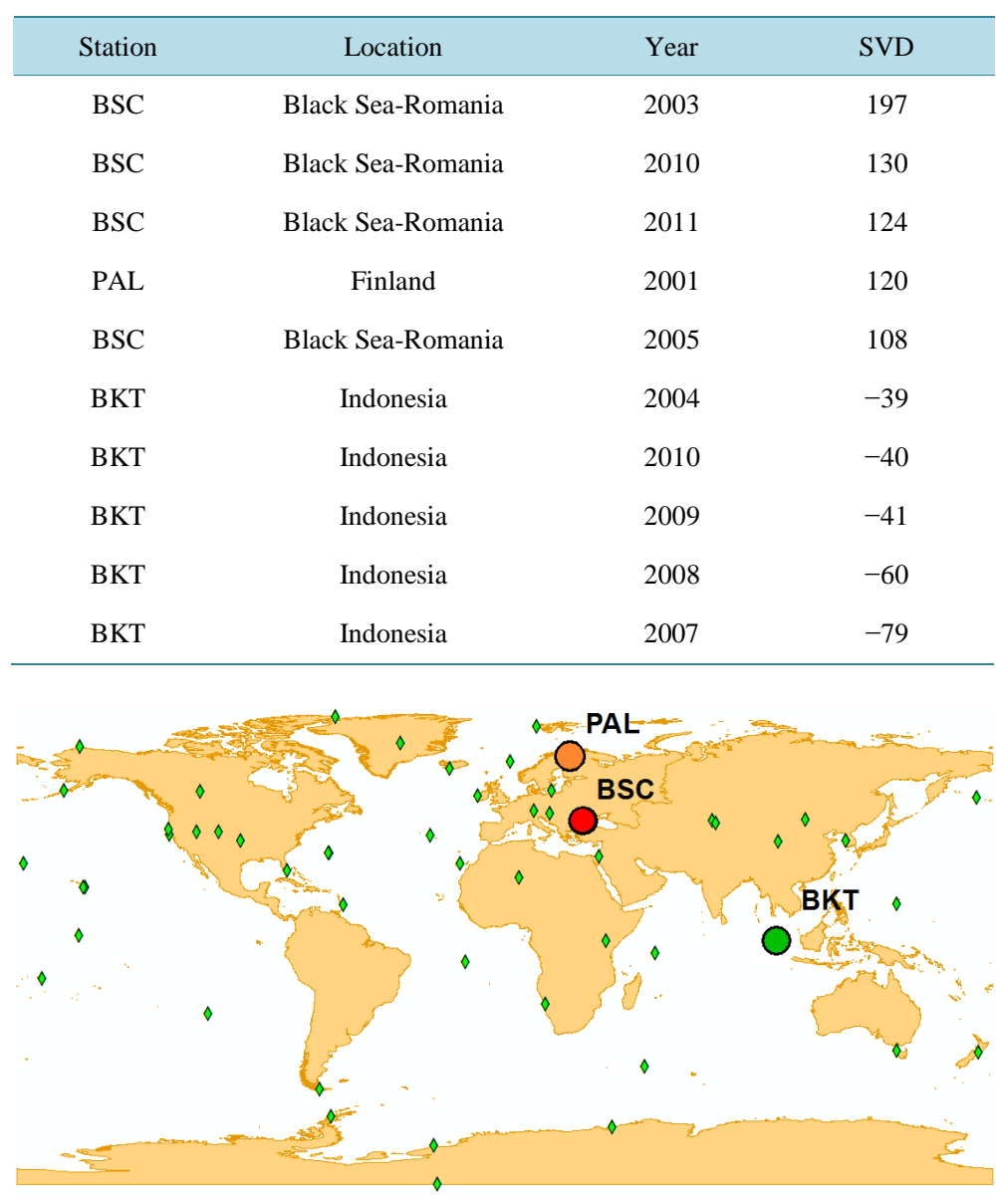

Figure 10. Locations of discussed stations.

mentioned in the previous sections, despite the extraordinary importance of preventing the growth of residual carbon dioxide in the atmosphere, the identification of factors that influence the emission and absorption of the gas is extremely low and rough. The method proposed in this paper is an innovative approach compared to previous studies, and expresses the results quickly and explicitly. It is good to use a method to evaluate the results of this study with cases of observation. In addition, because the residual quantity of atmospheric carbon dioxide is strongly dependent on the temperature, it is good to do this research, again with seasonal data, and the results reviewed.

\section{Acknowledgements}

I would like to deeply thank Dr. Ali Javidaneh who cooperated in the development of research ideas. And also Mr. Nima Ghasemloo and Dr. Hamid reza Ranjbar who helped me frankly in implementing the computer programs for this study.

\section{References}

[1] Atherton, J. (2012) Multiscale Remote Sensing of Plant Physiology and Carbon Uptake. Thesis for the Degree of Doctor of Philosophy to the University of Edinburgh, Edinburgh.

[2] Azizi, G. and Karimi, M. (2005) Thermal Trend in Passed 10 Years in Iran. Geographical Science Journal, 4, 22-29.

[3] Salahi, B. and Valizadeh, Kh. (2006) Thermal and Precipitation Changes Simulation in Tabriz by Doubling the Existence of $\mathrm{CO}_{2}$ in Atmosphere. Spatial Studies Institute of Geographic Researches, 62, 3-14. 
[4] Le Quéré, C., Raupach, M.R., Canadell, J.G., Marland, G., et al. (2009) Trends in the Sources and Sinks of Carbon Dioxide. Nature Geosciences, 2, 831-836. http://dx.doi.org/10.1038/ngeo689

[5] Tan, R.R. (2010) Determining Approximate Stackelberg Strategies in Carbon Constrained Energy Planning Using a Hybrid Fuzzy Optimisation and Adaptive Multi-Particle Simulated Annealing Technique. The Institution of Engineers, Malaysia, September 2010, 71-3

[6] Badeban, Z. and Zahedi, Gh. (2008) Considering the Carbon Sequestration in Forest Soil. Forest and Timber Production Journal, 62.

[7] Canadell, J.G., et al. (2007) Contributions to Accelerating Atmospheric $\mathrm{CO}_{2}$ Growth from Economic Activity, Carbon Intensity, and Efficiency of Natural Sinks. Proceedings of the National Academy of Sciences of the United States of America, 104, 18866-18870. http://dx.doi.org/10.1073/pnas.0702737104

[8] Denman, K.L., et al. (2007) Couplings between Changes in the Climate System and Biogeochemistry. In: Solomon, S., et al., Eds., IPCC Climate Change 2007: The Physical Science Basis, 499-587, Cambridge University Press, Cambridge.

[9] Fan, S., Gloor, M., Mahlman, J., Pacala, S., Sarmiento, J., Takahashi, T. and Tans, P. (1998) A Large Terrestrial Carbon Sink in North America Implied by Atmospheric and Oceanic Carbon Dioxide Data and Models. Science, 282, 442-446. http://dx.doi.org/10.1126/science.282.5388.442

[10] Manconi, A., Walter, T.R. and Amelung, F. (2007) Effects of Mechanical Layering on Volcano Deformation. Geophysical Journal International, 170, 952-958. http://dx.doi.org/10.1111/j.1365-246X.2007.03449.X 